\title{
"Transient structures": The effects of practice and distractor grouping on within-dimension conjunction searches
}

\author{
MARISA CARRASCO \\ New York University, New York, New York \\ DOLORES PONTE \\ Universidad de Santiago de Compostela, La Coruña, Spain \\ CRISTINA RECHEA \\ Universidad de Castilla-La Mancha, Albacete, Spain \\ and \\ MARÍA JOSÉ SAMPEDRO \\ Universidad de Santiago de Compostela, La Comina, Spain
}

\begin{abstract}
It has been stated that whereas between-dimension (color $\times$ orientation) conjunctions can be searched in a "parallel" fashion, within-dimension (color $\times$ color) conjunctions are necessarily searched in a "serial self-terminating" fashion (Wolfe et al., 1990). We explored the effects of practice (within 1-h experimental session) and distractor grouping on within-dimension conjunction search tasks. In Experiments 1 and 3, the stimuli were rectangles formed by two adjacent squares; in Experiment 2, the stimuli were plus signs formed by two segments and an intersection. In Experiments 1 and 2, observers were assigned to one of two experimental conditions: In one, all the distractors shared a simple feature (the color blue); in the other, distractors did not share that simple feature. In the first condition, search became more efficient with practice and observers' performance was characterized by a shallow reaction time $(\mathrm{RT}) \times$ set size slope; in the second condition, observers' performance did not improve as much with practice. We propose that the differential effects of practice between these two experimental conditions can be explained in terms of distractor grouping induced by the shared color of the distractors. Experiment 3 showed that, with practice, a shallow RT $\times$ set size slope characterized observers' search for a color $\times$ color target among four different distractors that shared a common color. The present results contradict a main tenet of some current visual search modelsnamely, that within-dimension conjunctions cannot be searched in parallel, and question the validity of using RT $\times$ set size slope functions to distinguish between preattentive versus attentive search.
\end{abstract}

Research in the field of visual search investigates how we detect, localize, and identify a specific target in a display. One of the central premises of visual search theories is that objects must first be decomposed into their basic features and then reorganized to form perceptual wholes farther along the visual pathways (e.g., Treisman, 1988; Treisman \& Gormican, 1988). It has been proposed that feature search is driven by a "parallel" process that is capable of registering the entire display when target and

This research was supported by the National Science Foundation (NYI Grant SBR-9357986) to M.C. and by La Conselleria de Educación y Ordenación Universitaria de la Xunta de Galicia (XUGA/21103B92) to C.R. We thank reviewers Herman Müller and Jeremy Wolfe for helpful comments on an earlier version of this paper and Cynthia Wei for her assistance in data collection and analysis of Experiment 3. Correspondence regarding this article should be addressed to $\mathrm{M}$. Carrasco, Department of Psychology, New York University, 6 Washington Place, New York, NY10003-6634 (e-mail: marisa@psych.nyu.edu) or to D. Ponte, Departamento de Psicología Social y Básica. Universidad de Santiago de Compostela, La Coruña. Spain (e-mail: psdponte@usc.es). distractor differences are clearly discernible. When these differences are less obvious, however, groups of items must be searched in order for the differences to become apparent, resulting in a "serial" search (Duncan \& Humphreys, 1989; Quinlan \& Humphreys, 1987; Treisman, 1993; Treisman \& Gormican, 1988; Wolfe, 1994; Wolfe, Cave, \& Franzel, 1989).

Between-dimension conjunctions (e.g., color $\times$ orientation: a red vertical target among red tilted and blue vertical distractors) have been reported to be searched in a "serial" fashion (e.g., Duncan \& Humphreys, 1989; Treisman, 1993; Treisman \& Gelade, 1980; Treisman \& Sato, 1990). However, some between-dimension conjunctions can be searched in a "parallel" fashion (e.g., Egeth, Virzi, \& Garbart, 1984; Nakayama \& Silverman, 1986; Wolfe et al., 1989). Nevertheless, it has been stated that withindimension conjunctions (e.g., color $\times$ color: a green and red square among green and blue and blue and red squares) are necessarily searched in a serial self-terminating fashion (Wolfe, 1994, 1996a; Wolfe, Friedman-Hill, \& Bil- 
sky, 1994; Wolfe et al., 1990). A parallel search is defined as one in which no additional time is required as the number of distractors increases, because all the items are isearch is defined as one in which a constant increment in the amount of time is required per each additional distractor because items are processed one at a time, and as one in which the slope for the trials where the target is present is half the slope for the trials where the target is absent (e.g., Egeth, Folk, \& Mullin, 1989; Treisman \& Gelade, 1980; Wolfe et al., 1990). However, Townsend $(1972,1990)$ has shown that a steep slope is consistent with a variety of parallel search models. For instance, each additional item could be processed at the same time but at a lower rate, as if limited resources were being distributed among more elements (e.g., Kinchla, 1992). Humphreys and Müller (1993) have shown, with their computational parallel processing model (SERR), that parallel processes can result in both linear and nonlinear and steep and shallow search slopes, and have reiterated Townsend's caveat in linking search functions to process models. Given the limitations with interpreting slopes to draw conclusions about whether a search is "parallel" or "serial," we will characterize search performance in our study by using shallow and steep slopes instead.

The goal of this study was to explore whether withindimension conjunctions would necessarily result in steep slopes. Note that none of the various color $x$ color experiments conducted by Wolfe et al. (1990) involved more than 330 trials per observer. We reasoned that if distractor grouping were induced by presenting distractors that shared a simple feature (e.g., half of the distractors would be red/blue and the other half would be blue/green while the target would be green/red), observers with a modest amount of practice would be able to develop a strategy that would allow them to perform efficient searches, even in a within-dimension task. In contrast, we expeeted that when distractors did not share a simple feature (e.g., half of the distractors would be blue/red and the other half green/yellow), grouping would not be facilitated and such an efficient search would not be attained.

According to the guided search model (GSM; Cave \& Wolfe, 1990; Wolfe, 1994, 1996a, 1996b; Wolfe \& Cave, 1990; Wolfe et al., 1989; Wolfe et al., 1990), the first stage of search, which detects all simple features in parallel, guides a second stage which is serial and takes place in limited areas of the visual field. During the first stage, the information activated by the simple features is added and registered in a global map of activation in which each location represents the probability of containing the target. In the second stage of processing, covert attention would be directed to the location with the highest level of activation. If the target is there, the search stops; if it is not there, it proceeds to the second highest level of activation, and so forth, until the target is found or until the leftover locations have a low enough level of activation for observers to decide that the target is not present.
In contrast to feature integration theory (Treisman, 1977, 1988; Treisman \& Gelade, 1980; Treisman \& Gormican, 1988), which has stated that conjunctions are searched in a serial way, GSM allows for attention to be guided by parallel processes. This yields an efficient search reflected in shallow reaction time $(\mathrm{RT}) \times$ set size slopes (e.g., Egeth et al., 1984; McLeod, Driver, \& Crisp, 1988; Nakayama \& Silverman, 1986; Poisson \& Wilkinson, 1992; Wolfe et al., 1989). GSM states that activation depends on the roles of both bottom-up and top-down processing, as well as stimulus salience and internal noise. Bottom-up processing (stimulus-driven) can be considered as a measure of how unusual an item in the display is. The more the target differs from the neighboring elements, the higher the activation produced. Top-down processing (user-driven) is determined by the difference between an item and the observer's knowledge about the designated target. The top-down activation, which is important for both feature and conjunction searches, increases as a function of the similarity between the target and the stimulus being processed. Both levels of activation are computed separately for each of the dimensional modules (e.g., color and orientation) in which the display information is represented (Cave \& Wolfe, 1990; Wolfe, 1994; Wolfe \& Cave, 1990; Wolfe et al., 1989; Wolfe et al., 1990).

According to Wolfe and his colleagues, searches for conjunctions of two features of a single dimension (e.g., color $\times$ color) are more difficult than conjunctions across dimensions (e.g., color $\times$ orientation). According to their argument, in a between-dimension search, the target is the stimulus with the highest activation level because it receives top-down activation from both dimensions. However, in a within-dimension search, activation emerges only from one dimension, and the features can be searched only in a serial fashion because they belong to the same dimension; different information competes for the same pathway, and that single pathway carries its information serially. If a target is red/green and the distractors are $\mathrm{red} /$ blue and blue/green, it is not possible to guide search independently toward the red items or the green items or away from the blue items. Conversely, it is possible to guide attention to an item defined by a conjunction of features that belong to different dimensions-for example, color $\times$ orientation -because activation emerges from two dimensions (e.g., Wolfe, 1994; Wolfe et al., 1994; Wolfe et al., 1990).

Two experimental issues are central for the present study: perceptual grouping and practice effects. There is general agreement that perceptual grouping occurs preattentively and that this organization should affect subsequent stages of processing (e.g., Beck, 1966, 1967, 1982; Bravo \& Blake, 1990; Duncan, 1984; Duncan \& Humphreys, 1989; Julesz, 1980; Neisser, 1967; Prinzmetal \& Banks, 1977; Treisman, 1982; but see Ben-Av, Sagi, \& Braun, 1992; Palmer \& Rock, 1994). Grouping has been found to play a role in both feature and conjunction searches. Indeed, following such perceptual grouping prin- 
ciples as similarity and proximity, visual search models claim that search is facilitated by greater target/distractor discriminability and efficient grouping of homogeneous distractors but is hindered by grouping between target and distractors and an increase in the number of different distractor groups. Perceptual grouping among distractors is beneficial because the more similar the distractors are to each other, the stronger the grouping effects among them and the more efficiently they can be rejected (Bundesen \& Pedersen, 1983; Carrasco \& Chang, 1995; Duncan, 1995; Duncan \& Humphreys, 1989, 1992; Farmer \& Taylor, 1980; Grossberg, Mingolla, \& Ross, 1994; Humphreys, Quinlan, \& Riddoch, 1989; McLeod et al., 1988; Nakayama \& Silverman, 1986; Poisson \& Wilkinson, 1992; Treisman, 1982, 1993; Treisman \& Gormican, 1988; Treisman \& Sato, 1990; Wolfe, 1992, 1994; Wolfe et al., 1989).

Gestalt theory has shown that by manipulating the color similarity and the proximity of stimuli, experimenters can create displays that "naturally" seem to group together (Banks \& Prinzmetal, 1976; Beck, 1982; Pomerantz, 1981). Color coding the items in a display affects the degree of perceived similarity and reduces the time required to locate a target in a visual scene because groups of items resulting from color similarity may be treated as units (e.g., Bundesen \& Pedersen, 1983; Carrasco \& Chang, 1995; Eriksen, 1952, 1953; Hitt, 1961; Kahneman \& Henik, 1981). We used color to induce distractor grouping in this study because of its effectiveness in facilitating the organization of items.

The second central issue for this study is that of practice. It has been shown that the search pattern is affected by extensive practice (reviewed in Kinchla, 1992). For instance, some tasks described by steep RT $\times$ set size slopes (e.g., convergence and closure) can be described by shallow RT $\times$ set size slopes after a few hundred trials. These authors found that learning in visual search was not task specific (Sireteanu \& Rettenbach, 1995; but see Treisman, Vieira, \& Hayes, 1992). With practice (1,600 trials), the slopes of the search functions decreased until they became nearly flat when targets differed from distractors only in the relative position of component features (e.g., a black and white target among white and black distractors; Heathcote \& Mewhort, 1993). In contrast, no practice effects appeared after 6,144 trials when the stimuli were pairs of dashes and plusses varying in spatial position (e.g., dash above or below plus; Logan, 1994). These inconsistent results could be explained by the fact that Heathcote and Mewhort (1993) used stimuli that could be considered as between-dimension conjunctions of color $\times$ spatial position and brightness $\times$ spatial position and a "consistent mapping" procedure (Experiments 1 and 2), whereas Logan (1994) used stimuli that could be considered as between-dimension conjunctions of form $\times$ spatial position and a "varied mapping" procedure. The circumstances under which extensive practice leads to perceptual automaticity have been investigated by several authors (e.g., LaBerge, 1975; Logan, 1988; Schneider, Dumas, \& Shiffrin, 1984; Shiffrin \& Schneider, 1977).

\section{EXPERIMENTS}

In this study, we explored the effects of distractor grouping and a modest amount of practice (within 1-h experimental sessions) on within-dimension conjunction searches. There were two experimental conditions in each of Experiments 1 and 2 . In the first condition, observers performed a standard color $\times$ color conjunction: They searched for a red/green target among red/blue and blue/green distractors. There were two differences between this condition and Wolfe et al.'s (1990) Experiment 1: (1) Because we were interested in studying practice effects, we included more trials in our experiments $(1,280$ trials in Experiment 1 and 1,008 trials in Experiment 2 vs. 330 trials in Wolfe et al.'s experiment); and (2) because we were interested in isolating the color variable in a within-dimension conjunction, in our searches we kept the relative spatial location of the colors forming the targets and the distractors constant - that is, a green/red target among green/blue and blue/red distractors (Figures 1 and 2). Wolfe et al.'s color $\times$ color target could be either red/green or green/red, and their distractors were red/blue, blue/red, green/blue, and blue/green . Given that allowing the relative spatial location to vary increases uncertainty, we kept relative spatial location constant and thereby minimized uncertainty. This allowed us to compare observers' performance in within-dimension conjunctions with that in between-dimension conjunctions in which observers search for one prespecified target (e.g., a red tilted target among red vertical and blue tilted distractors; Carrasco \& Frieder, 1997; Egeth et al., 1984, Wolfe et al., 1989). In the second condition of both Experiment $l$ and Experiment 2, observers performed a modified color $\times$ color conjunction (Figure 1); they searched for a red/green target among red/blue and yellow/green distractors (Experiment 1) and among red/blue and pink/green distractors (Experiment 2).

In the first condition, distractor grouping was induced because distractors shared a feature (blue); in the second condition, grouping was not facilitated because the distractors did not share a common color. We reasoned that if distractor grouping was induced via the shared color, observers with practice would develop a strategy that would result in shallow RT $\times$ set size slopes, even in a within-dimension task. In contrast, if distractor grouping was not facilitated, even with practice, the searches would result in steep RT $\times$ set size slopes.

In Experiment 3, we investigated the effect of practice (within a $1-\mathrm{h}$ experimental session) while replicating Wolfe et al.'s (1990) Experiment 1, in which the relative spatial location of the components of the target and distractors varied (Figure 1). Because the target could be red/ green or green/red and there were four types of distractors in each display — red/blue, blue/red, green/blue, and blue/green-we expected a search that was less efficient than that in the previous experiments. Notwithstanding the greater heterogeneity of the distractors in this experiment, we hypothesized that the common blue color the 


\section{EXPERIMENT 1}

Condition 1
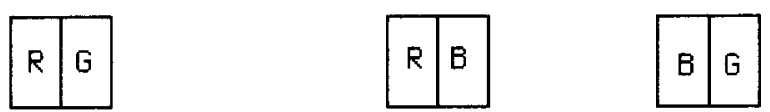

Condition 2
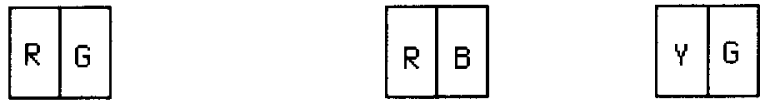

\section{EXPERIMENT 2}

Condition 1
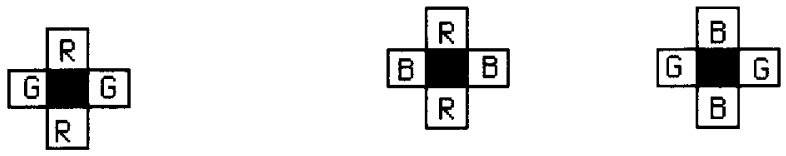

Condition 2
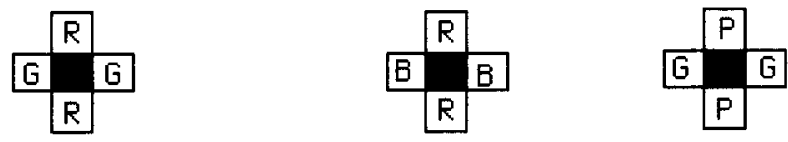

\section{EXPERIMENT 3}

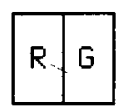

or

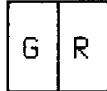

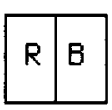

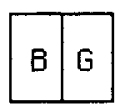

and

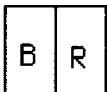

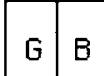

Figure 1. A schematic representation of the target and distractors used in the color $\times$ color conjunctions of this study $(R=$ red, $G=$ green, $B=$ blue, $Y=$ yellow, $P=$ pink).

distractors shared could favor grouping, which, with practice, would benefit the search to a large degree and allow shallow RT $\times$ set size slopes to be attained.

The GSM has considered the finding that color $\times$ color conjunctions are searched in a "serial self-terminating" fashion to represent an important limitation on the ability of the parallel stage of visual processing to guide the subsequent serial deployment of attention (Wolfe et al., 1990). If search performance in the present experiments were to improve as a function of practice so that the search would be best characterized, by RT $\times$ set size slopes, as being "attentive" with little practice and "preattentive" after some practice, then the structure of the parallel stage of processing proposed by GSM regarding color $\times$ color conjunctions (Cave \& Wolfe, 1990; Wolfe, 1994; Wolfe et al., 1990) would be disputed. Furthermore, if for modestly practiced observers search performance varied from reflecting "attentive" to "preattentive" processes, the stability and validity of this distinction would be brought into doubt.

\section{Experiment 1}

\section{Method}

Observers. Thirty undergraduates at the Department of Psychology of the University of Santiago de Compostela, voluntarily participated in a $1-h$ session in partial fulfillment of introductory 


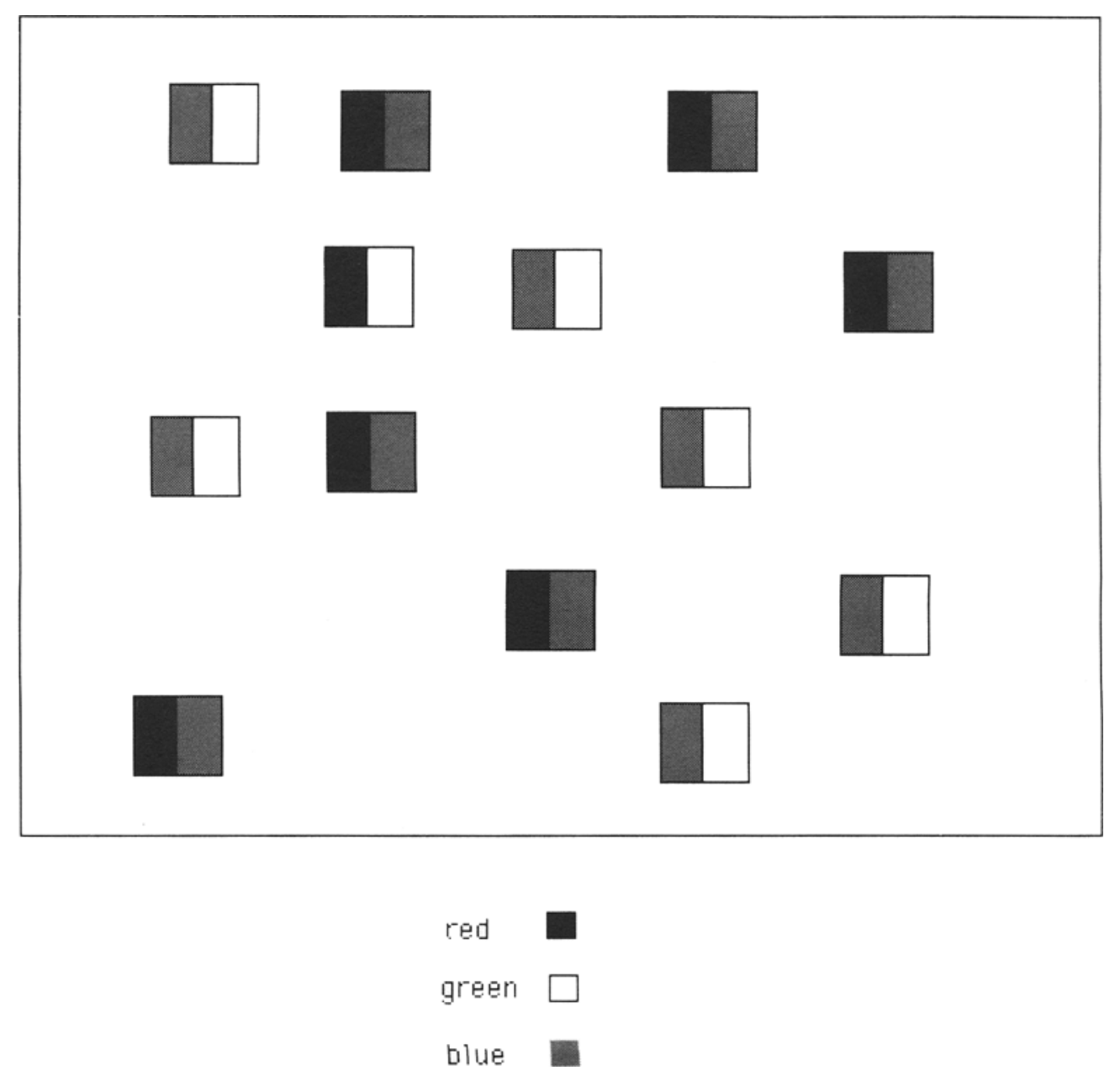

Figure 2. An example of a display in Experiment 1's Condition 1. Observers were asked to decide whether a target (red/green) was present or absent amid red/blue and blue/green distractors.

psychology courses. All had normal or corrected-to-normal vision and were naive as to the purpose and method of the experiment.

Apparatus and Stimuli. The stimuli were presented on an IBM PS/ 2 mictocomputer with a VGA graphics card of $640 \times 480$ pixels and a high-resolution RGB color monitor (Type $8513 \mathrm{~S} / \mathrm{N} 55-$ V4825). Stimuli's luminance (lum) and chromaticity were measured with a Textronix $J 17$ LumaColor and a Textronix J1803 luminance head or a Textronix $\mathrm{J} 1803$ chromaticity head.

Each display consisted of $4,8,12$, or 16 items of $0.7 \times 0.5 \mathrm{~cm}$, subtending $0.44^{\circ}$ (height) $\times 0.32^{\circ}$ (width) of visual angle, divided in the center so that two contiguous vertical rectangles were formed. Consistent mapping was used (Schneider \& Shiffrin. 1977: Shiffrin \& Schneider, 1977); target and distractors were the same throughout the experiment. The target's left half was red (luminance $=$ $27.6 \mathrm{~cd} / \mathrm{m}^{2}$ : coordinates $.632, .350$ in standard CIE color space); its right half was green (lum $=31.5 \mathrm{~cd} / \mathrm{m}^{2} ;$ CIE coordinates $=.275$, $.610)$. Each condition had two types of distractors. In Condition I (shared color), one type of distractor had a red left half and a blue (lum $=21.3 \mathrm{~cd} / \mathrm{m}^{2}:$ CIE coordinates $\left.=.175, .108\right)$ right half; the other type of distractor had a green right half and a blue left half (Figures 1 and 2). In Condition 2 (nonshared color), one type of distractor had a red left half and a blue right half: the other type of distractor had a green right half and a yellow (lum $=138 \mathrm{~cd} / \mathrm{m}^{2}$; CIE coordinates $=.373,482)$ left half (Figure 1$)$. The stimuli in both con- ditions were presented against a gray-blue (lum $=6 \mathrm{~cd} / \mathrm{m}^{2} ; \mathrm{ClE}$ coordinates $206, .192$ ) background. The items were scattered among 425 positions on a rectangular grid composed of 17 rows and 25 columns, and the target randomly appeared in any position. The overall dimensions of the display were $11.9 \times 12.5 \mathrm{~cm}$. On the basis of a viewing distance of $1 \mathrm{~m}$, this subtended a $7.5^{\circ}$ (height) $\times 7.9^{\circ}$ (width) visual angle.

Design and Procedure. A mixed-factorial design with four independent variables was used: one between subjects (Condition 1 vs. Condition 2) and three within subjects (Blocks 1, 2, 3, and 4; set sizes $4,8,12$, and 16 ; and target present vs. target absent). $\mathrm{RT}$, measured from the onset of the display, and accuracy were the dependent variables. Observers had eight practice trials before each of four experimental blocks. which consisted of 320 randomized trials, for a total of 1.280 experimental trials per observer. In each trial. following a fixation point that appeared in the middle of the screen for $1 \mathrm{sec}$, the display was present until observers responded. The screen remained gray blue during the 1 -sec interstimulus interval.

The observers were told that half of the displays would contain a target at any location of the visual field, and that their task was to press the "S" key (si, yes) on the computer keyboard if the target was present or the " $\mathrm{N}$ " key (no) if the target was absent. The observers were instructed to respond as rapidly and as accurately as possible, since both speed and accuracy were to be recorded. 


\section{CONDITION 1}

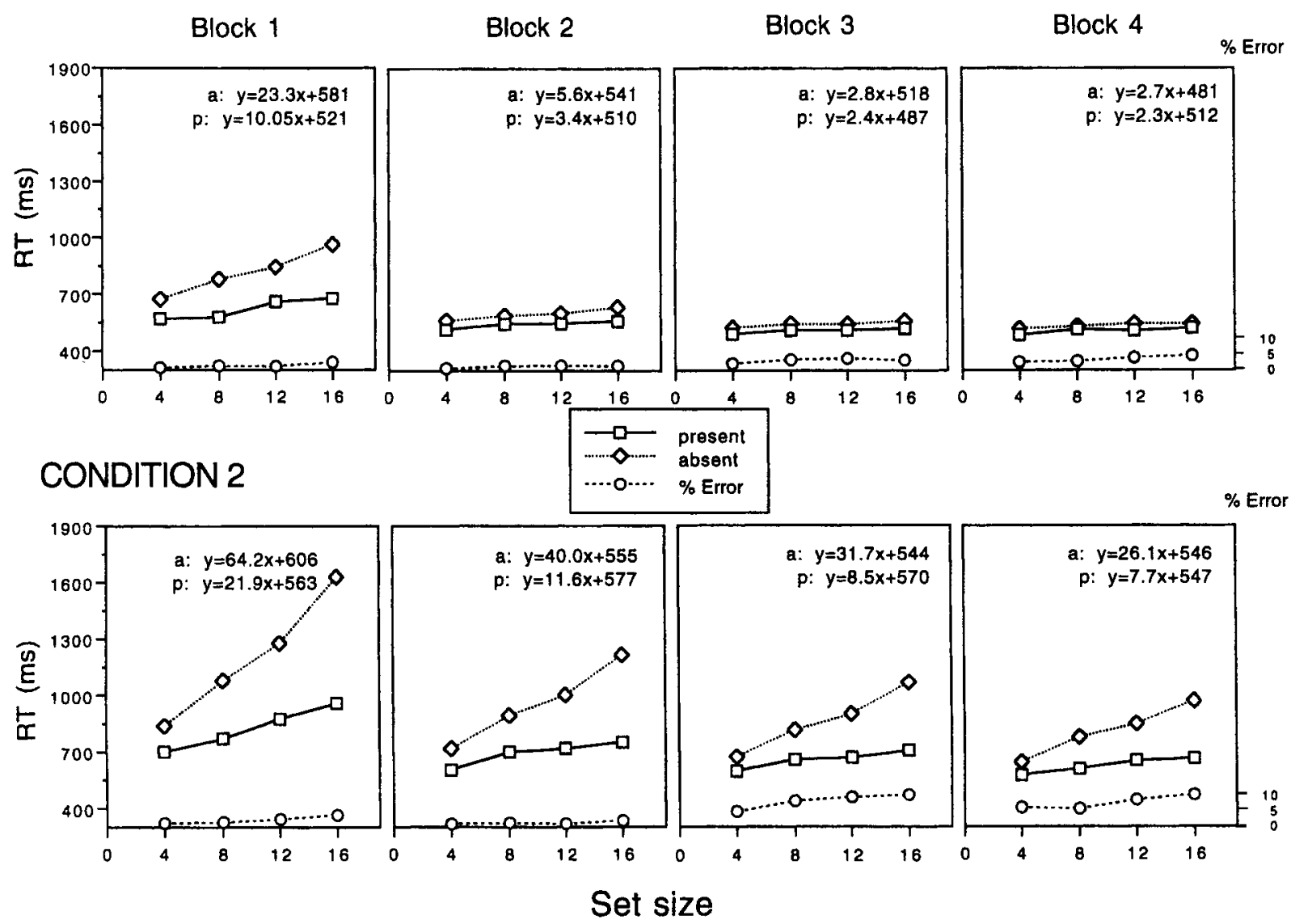

Figure 3. Search performance in Experiment 1: RT and \% error as a function of set size for a color $\times$ color conjunction (red/green) when the distractors shared a common feature (red/blue and blue/green, Condition 1) and when they did not (red/blue and yellow/green, Condition 2).

\section{Results}

Figure 3 depicts the observers' mean correct RT and error rates as a function of set size for the four experimental blocks of each condition, shared color (Condition 1) on the top panel and nonshared color (Condition 2) on the bottom panel. The linear fit's intercepts of these functions show that the minimum response time was faster for present than for absent trials. The search functions relating $\mathrm{RT} \times$ set size are indexed by the slope values, which will be discussed below.

Table 1 shows the results of the four-way analysis of variance (ANOVA) performed on the correct RT (betweensubjects, condition; within-subjects, block $\times$ target $\times$ set size). All main effects and interactions discussed here were statistically significant $(p<.05)$. All four main effects were significant, with observers detecting the target faster in Condition 1 than in Condition 2-that is, when distractors shared a color than when they did not; search time decreased progressively from the first to the fourth block; detecting the presence of the target was faster than detecting its absence; and search time increased as the display contained more items.
The interactions of condition $x$ target and condition $x$ set size indicate that the difference between absent and present trials as well as the effect of set size were more pronounced for Condition 2 than for Condition 1. The interactions of block $\times$ target and block $\times$ set size illustrate that, with more practice, the effects of target and of set size decreased. Likewise, the interaction of target $\times$ set size, which shows the growing difference between present and absent trials as set size increased, diminished with practice, as assessed by the three-way interaction of block $\times$ target $\times$ set size. Central to this study is the interaction of condition $\times$ block, which indicates that the practice effect differed when distractors shared a color and when they did not. Furthermore, the interaction of these two factors with set size (condition $\times$ block $\times$ set size) illustrates that this difference was more pronounced for the largest set sizes.

For the accuracy data, an ANOVA indicated that all four main effects were significant: Observers were more accurate when the distractors shared a color (Condition 1) than when they did not (Condition 2$)[F(1,28)=34.60$, $p<.001]$, for the absent than for the present targets 
Table 1

ANOVA Results for RT Data in Experiment 1

\begin{tabular}{lccc}
\hline \multicolumn{1}{c}{ Factor } & $d f$ & $F$ & $p$ \\
\hline Condition (C) & 1,28 & 18.17 & $<.001$ \\
Block (B) & 3,84 & 96.75 & $<.001$ \\
Target (T) & 1,28 & 23.06 & $<.001$ \\
Set size (S) & 3,84 & 24.88 & $<.001$ \\
$\mathrm{C} \times \mathrm{B}$ & 3,84 & 2.84 & $<.05$ \\
$\mathrm{C} \times \mathrm{T}$ & 1,28 & 6.36 & $<.05$ \\
$\mathrm{C} \times \mathrm{S}$ & 3,84 & 8.34 & $<.001$ \\
$\mathrm{~B} \times \mathrm{T}$ & 3,84 & 44.89 & $<.001$ \\
$\mathrm{~B} \times \mathrm{S}$ & 9,252 & 41.83 & $<.001$ \\
$\mathrm{~T} \times \mathrm{S}$ & 3,84 & 14.07 & $<.001$ \\
$\mathrm{C} \times \mathrm{B} \times \mathrm{T}$ & 3,84 & 0.85 & n.s. \\
$\mathrm{C} \times \mathrm{B} \times \mathrm{S}$ & 9,252 & 3.00 & $<.05$ \\
$\mathrm{C} \times \mathrm{T} \times \mathrm{S}$ & 3,84 & 6.80 & $<.001$ \\
$\mathrm{~B} \times \mathrm{T} \times \mathrm{S}$ & 9,252 & 20.53 & $<.001$ \\
$\mathrm{C} \times \mathrm{B} \times \mathrm{T} \times \mathrm{S}$ & 9,252 & 1.04 & n.s. \\
\hline
\end{tabular}

$[F(1,28)=99.94, p<.001]$, for the smaller than for the larger set sizes $[F(13,84)=57.43, p<.001]$, and for the last than for the first blocks $[F(3,84)=93.28, p<.001]$. However, the interactions of condition $\times$ block $[F(3,84)=$ 23.96, $p<.001]$ and condition $\times$ set size $[F(3,84)=$ $10.36, p<.001]$ revealed that the effects of block and set size were more pronounced for Condition 2 than for Condition 1 . The interactions of block $\times$ set size $\times$ condition $[F(9,252)=2.68, p<.005]$ emerged because the interaction between set size and block was significant only in Condition 2.

Overall, RT was faster when the target was present than when it was absent, but there were more errors made with the present trials. This indicates that a speed-accuracy tradeoff occurred. Although this pattern of results has often been found for both feature and conjunction searches, while some authors have analyzed the error rates (Enns \& Rensink, 1990a, 1990b; Humphreys et al., 1989; Klein \& Farrell, 1989; Moraglia, 1989a; Wolfe et al., 1989), others have simply mentioned them (e.g., Egeth et al., 1984; Moraglia, 1989b; Treisman, 1982; Treisman \& Gormican, 1988; Treisman \& Sato, 1990). More important for the present experiment is the fact that there was no speed-accuracy tradeoff in terms of condition between RT and error rates; the first condition was faster and more accurate than the second condition. In addition, there was no speed accuracy tradeoff in terms of set size between RT and error rates; errors increased as RT increased, indicating that observers were not simply trading speed for accuracy (Enns \& Rensink, 1990a, 1990b). This is a common finding, considered to be the opposite of a speed-accuracy tradeoff (Wolfe, 1994), that has not precluded analysis of slopes (Duncan \& Humphreys, 1989; Enns \& Rensink, 1990a, 1990b; Wolfe, 1994).

To better understand the effect of practice on the search functions for both conditions, we compared their linear regression slopes as obtained by the minimum least squares method. When the target was present and the distractors shared a color, the slope was about $10 \mathrm{msec}$ since the first block (Figure 3, top panels). Wolfe et al.'s (1990) steeper slopes for their color $\times$ color search $(20$ and $40 \mathrm{msec} /$ item for the present and absent targets, respectively) may be due to the fact that, as described above, their target could be either red/green or green/red while the spatial location of our target was kept constant, that is, green/red (see General Discussion). According to conventional criteria, this shallow slope would be assumed to indicate that detection occurred in a "parallel" fashion (e.g., Cave \& Wolfe, 1990; Duncan \& Humphreys, 1989; Enns \& Rensink, 1990a, 1990b; Treisman, 1977; Treisman \& Gelade, 1980; Treisman \& Gormican, 1988; Wolfe \& Cave, 1990; Wolfe et al., 1989). With practice, target detection continued to improve, as assessed by the decrement in the slope. When the target was absent, there was a steep search function in the first block; with practice, it became shallower and more efficient.

The nature of the visual search is also commonly assessed by the absent/present slope ratio criterion. A 2:1 absent/present ratio is considered to index a serial selfterminating search. Search for the present target is terminated once it is found (on average, after half the items in the display have been examined), whereas determination of the target's absence requires that all items be examined first. In contrast, a 1:1 absent/present ratio is considered to index an exhaustive search (e.g., Pashler, 1987; Treisman \& Gelade, 1980; Wolfe, 1994; but see Van Zandt $\&$ Townsend, 1993). Figure 3 (top panels) illustrates that, with practice, when distractors shared a color the absent/ present ratio decreased, from 2.3:1 in the first block to 1.7:1 in the second block, to $1.2: 1$ in the third block, and to $0.9: 1$ in the fourth and last block. This decrement in the absent/present ratio, which supports the target $\times$ set size interaction, indicates that the effects of practice were more pronounced for the absent than for the present trials, and suggests that practice evoked a change in the search strategy to the point that both present and absent trials were efficiently processed. A 1:1 absent/present ratio has previously been obtained for conjunctions $(\mathrm{Ca}-$ rrasco, Evert, Chang, \& Katz, 1995; Carrasco \& Yeshurun, 1998; Friedman-Hill \& Wolfe, 1995; Ponte, Rechea, \& Sampedro, 1995; Rechea, Ponte, \& Risso, 1992).

Figure 3 (bottom panels) depicts the slopes when distractors did not share a color. The slopes were steeper than when the distractors did share a color, reflecting the greater difficulty of this search task. The absent/present ratio was approximately constant across blocks, $\pm 3: 1$ (2.9:1 for the first block; 3.4:1 for the second block; 3.7:1 for the third block; and 3.4:1 for the fourth block). This suggests that practice did not elicit a change in the search strategy; the search remained serial self-terminating. In both conditions, the linear fit's intercepts show that the minimum RT was faster for present than for absent trials and that, in both cases, the search became faster with practice.

Lastly, according to the serial self-terminating model, RT variability should increase more as a function of set size for present than for absent trials (Shiffrin \& Schneider, 1977). However, our results showed the opposite pat- 
tern, RT variability increased more for the absent than for the present targets in the four blocks of this experiment.

\section{Experiment 2}

In this experiment, we investigated whether the efficient search for a color $X$ color conjunction that we found in Experiment 1 depended on the particular shape we had used. In addition, we evaluated two alternative explanations for this efficient search:

(1) Color assimilation: Color assimilation between red and green occurs when the luminance of the color inducers is below that of the background (de Weert \& Spillman, 1995). Even though, in our study, the luminance of all the stimulus colors was higher than that of the background, the green/red target could have had a slight yellow cast which could have served as an effective cue in Condition 1 (red/blue and blue/green distractors). This yellow cast, on the other hand, could have hampered the search in Condition 2 because one of the distractors contained yellow, and perceived grouping between target and distractors in a display reduces search efficiency (Bundesen \& Pedersen, 1983; Carrasco \& Chang, 1995; Duncan \& Humphreys, 1989, 1992; Poisson \& Wilkinson, 1992).

(2) Local contrast: Given that the two colored regions of each stimulus were directly in contact with each other, observers could have learned to search for high local color contrast at the bordering line of the two colors (Wolfe et al., 1990). Note, however, that because this possibility would have been the same for both Conditions 1 and 2 , local contrast could not be responsible for the differential performance in both conditions.

To rule out these two alternative explanations, we used a color $\times$ color conjunction with a different shape, a plus sign, in which the colored regions were not directly adjacent to one another and the intersection of the segments was black. A similar stimulus has been used by Wolfe et al. (1990, Experiment 5). As in the previous experiment, there were two conditions: in the first, distractors shared a color (red/blue and blue/green distractors); in the second, distractors did not share a color (red/blue and pink/green distractors).

\section{Method}

Observers. Ten undergraduates from the New York University subject pool participated as observers in each of the two conditions of this experiment. All 20 observers had normal or corrected-tonormal vision and were naive as to the purpose of the study. They had not participated in the previous experiment.

Apparatus and Stimuli. The stimuli were presented using Vscope (Enns \& Rensink, 1992) on a 17 -in. monitor of a Power Macintosh 7500/100 computer, whose frame rate equals 13.4 msec. All the items appeared on a white background. In Condition 1, the distractors shared a color; observers searched for a plus-sign target with a green vertical and a red horizontal segment among plus-sign distractors with a green vertical and a blue horizontal segment and a blue vertical and a red horizontal segment. In Condition 2, the distractors did not share a color; observers searched for the same target among plus sign distractors with a green vertical and a pink horizontal segment and a blue vertical and a red horizontal segment. Each segment subtended $1.5^{\circ} \times 0.03^{\circ}$ of visual angle. The inter- section of the vertical and horizontal components was black, so the colored regions were not directly adjacent to one another (Figure 1). The gap between the centers of the items subtended $2.8^{\circ}$. The brightness of the green and red $(.280, .595$ and $.625, .340$ in standard CIE color space, respectively) were at $70 \%$ and $100 \%$ of maximum monitor brightness, respectively. (A pilot experiment had indicated that the discriminability of green and red was the same at these brightness levels.) A small fixation dot was present in the center of the screen throughout the experiment. A plus $\left(0.25^{\circ} \times 0.25^{\circ}\right)$ or a minus $\left(0.25^{\circ} \times 0.1^{\circ}\right)$ sign served as the feedback, and was presented in the center of the screen. On each trial, the items were presented in one of four possible set sizes $(2,6,10$, or 14) and were scattered randomly among 25 positions on a square grid composed of five rows $\times$ five columns, which subtended a $12.5^{\circ} \times 12.5^{\circ}$ of visual angle.

Design and Procedure. A mixed-factorial design with four independent variables was used: one between-subjects (Condition 1 vs. Condition 2), and three within-subjects (Blocks 1, 2, 3, and 4; set sizes $2,6,10$, or 14 ; and target present vs. absent). The target was present in half of the trials. The displays were present until observers responded. The observers were read instructions specifying the target, and asking them to indicate, as rapidly and accurately as possible, whether or not the target was present in the display. Each observer was given 100 practice trials. There were four experimental blocks of 252 trials each for a total of 1,008 trials per observer. After each block, the observers could rest for a couple of minutes while they were given feedback about their performance. Observers responded by pressing a key on the computer keyboard with the index or middle finger of their dominant hands. Half the observers used the index finger for a "yes" response, and the other half used the middle finger. Immediately after the observers responded, the appropriate feedback sign was presented for $1 \mathrm{sec}$.

\section{Results}

Figure 4 depicts the observers' mean correct RT and error rates as a function of set size for the four experimental blocks of each condition, shared color (Condition 1) in the top panel and nonshared color (Condition 2) in the bottom panel. The linear fit's intercepts of these functions show that the minimum response time was faster for present than for absent trials. The search functions relating RT $\times$ set size are indexed by the slope values, which will be discussed below.

A four-way ANOVA was performed on the correct RT (between subjects, condition; within-subjects, block $X$ target $X$ set size; Table 2 ). All main effects and interactions discussed were statistically significant $(p<.05)$. A main effect indicated that observers' search time decreased progressively from the first to the fourth block. The interactions of block $\times$ target and block $\times$ set size revealed that, with more practice, the effects of targettarget presence was detected faster than its absence - and set size-search time increased as the display contained more items - decreased. As in the previous experiment, the interaction of condition $\times$ block indicated that the effect of block was more pronounced for the shared-color than for the nonshared-color condition. Moreover, the interaction of these two factors with target (condition $x$ block $\times$ target) illustrates that this difference was more pronounced for absent trials, and the interaction of condition $\times$ block $\times$ set size indicates that the stronger practice effect for the shared-color than for the nonshared- 


\section{CONDITION 1}
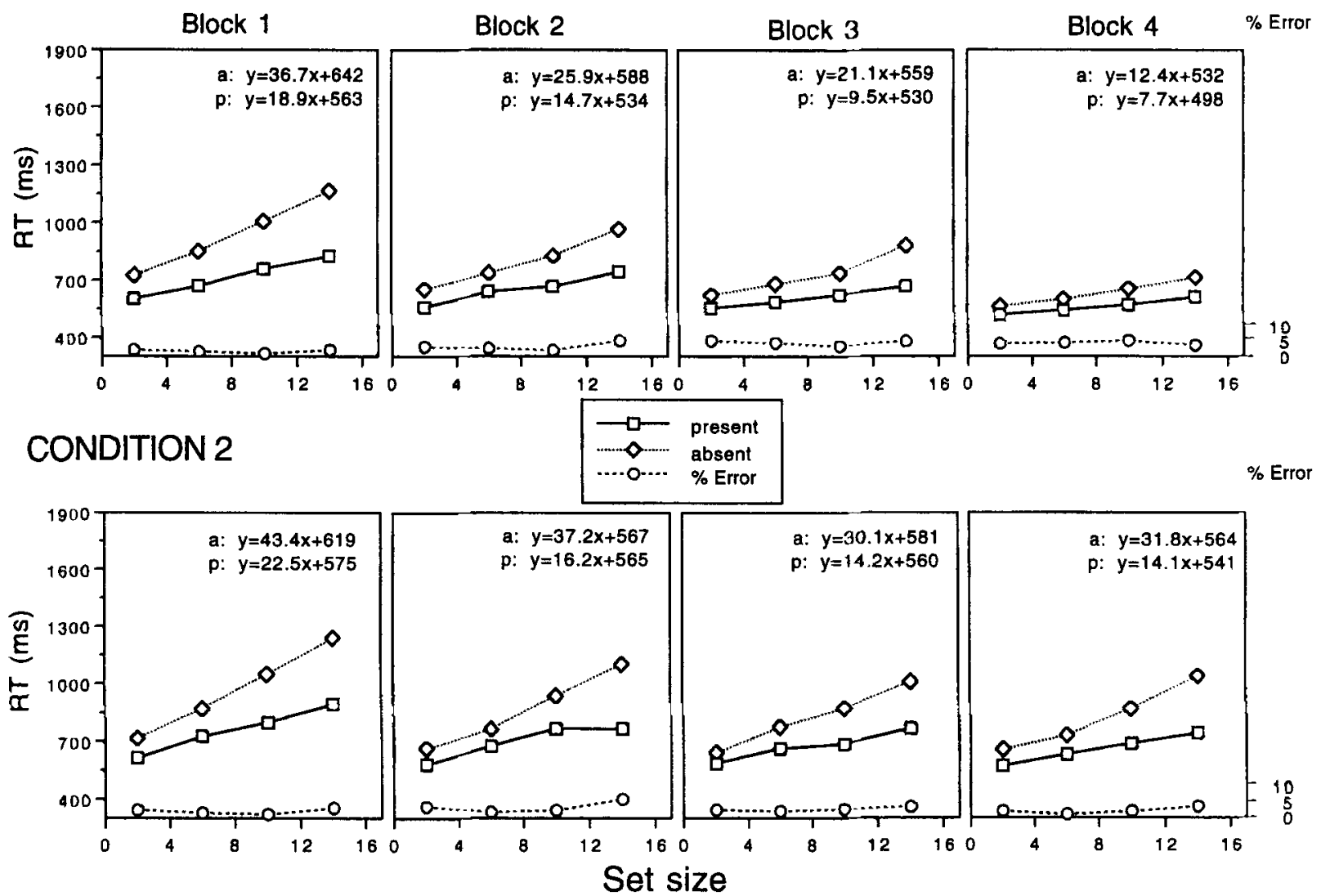

Figure 4. Search performance in Experiment 2: RT and \% error as a function of set size for a color $\times$ color conjunction (red/green) when the distractors shared a common feature (red/blue and blue/green, Condition 1) and when they did not (red/blue and pink/green, Condition 2).

color condition was more pronounced for the largest set sizes. For the accuracy data, an ANOVA indicated that the only main effect was that of target: Observers were more accurate for the absent than for the present targets $[F(1,18)=5.96, p<.05]$. This common finding was discussed in Experiment 1. None of the relevant interactions were significant (e.g., condition $\times$ block and condition $\times$ set size).

As in Experiment 1, in the shared-color condition, the slopes became shallower with practice (Figure 4, top panels) to the point that they could no longer be considered to reflect a limited-capacity serial search (e.g., Treisman \& Gormican, 1988). Although practice also aided performance in the nonshared-color condition (Figure 4, bottom panels), the slopes did not become as shallow and there was no further improvement from the third to the fourth blocks. Note that the slopes were shallower than those for the plus sign of Wolfe et al. (1990; present, 38.8, and absent, $74 \mathrm{msec} /$ item), even in the first block for the shared-color condition, although the absent-to-present ratio was 1.9 in both studies. (We discuss this difference in the General Discussion.) As in the previous experiment, in contrast to a prediction of a serial self-terminating model
(Shiffrin \& Schneider, 1977), RT variability increased more for the absent than for the present trials.

In sum, using a plus-sign color $\times$ color conjunction, in which the colored regions were not directly adjacent to one another and the intersection of the segments was black, we found converging evidence for the findings of Experiment 1 -a within-dimension color $\times$ color conjunction can be searched efficiently-and ruled out two alternative explanations for such findings, color assimilation and color contrast.

\section{Experiment 3}

In this experiment, we investigated the effect of practice while replicating Wolfe et al.'s (1990) Experiment 1. Observers performed a color $\times$ color conjunction task when the target could be red/green or green/red and the distractors were red/blue, blue/red, green/blue, and blue/green. Allowing the relative spatial location of the color components of the target and the distractors to vary increased uncertainty at both top-down and bottom-up levels. According to the former, observers had to search for one of two possible targets, and according to the latter, the display was more heterogeneous and "noisier" 
Table 2

ANOVA Results for RT Data in Experiment 2

\begin{tabular}{lrrl}
\hline \multicolumn{1}{c}{ Factor } & $d f$ & $F$ & $p$ \\
\hline Condition (C) & 1,18 & 1.95 & n.s. \\
Block (B) & 3,18 & 12.03 & $<.001$ \\
Target (T) & 1,18 & 3.42 & $<.10$ \\
Set size (S) & 3,54 & 2.43 & $<.10$ \\
$\mathrm{C} \times \mathrm{B}$ & 3,18 & 3.18 & $<.05$ \\
$\mathrm{C} \times \mathrm{T}$ & 1,18 & 0.53 & n.s. \\
$\mathrm{C} \times \mathrm{S}$ & 3,54 & 2.64 & $<.058$ \\
$\mathrm{~B} \times \mathrm{T}$ & 3,54 & 9.86 & $<.001$ \\
$\mathrm{~B} \times \mathrm{S}$ & 9,54 & 4.46 & $<.001$ \\
$\mathrm{~T} \times \mathrm{S}$ & 3,54 & 0.38 & n.s. \\
$\mathrm{C} \times \mathrm{B} \times \mathrm{T}$ & 3,54 & 4.72 & $<.001$ \\
$\mathrm{C} \times \mathrm{B} \times \mathrm{S}$ & 9,54 & 2.35 & $<.05$ \\
$\mathrm{C} \times \mathrm{T} \times \mathrm{S}$ & 3,54 & 1.55 & n.s. \\
$\mathrm{B} \times \mathrm{T} \times \mathrm{S}$ & 9,162 & 1.44 & n.s. \\
$\mathrm{C} \times \mathrm{B} \times \mathrm{T} \times \mathrm{S}$ & 9,162 & 1.16 & n.s. \\
\hline
\end{tabular}

because there were four types of distractors, and search performance deteriorates as distractor heterogeneity increases (e.g., Duncan \& Humphreys, 1989). For these reasons, we expected the search to be less efficient than in the previous experiments. However, because all four distractor types shared blue as a common color, notwithstanding the greater heterogeneity of the display, we hypothesized that, with practice, observers would be able to group the distractors and the search would be facilitated so that RT $\times$ set size slopes would become shallower.

\section{Method}

Observers. Ten undergraduates from the NYU subject pool participated as observers in this experiment. All observers had normal or corrected-to-normal vision and were naive as to the purpose of the study. They had not participated in the previous experiments.
Stimuli. Each display consisted of $2,6,10,14,18$, or 22 items of $0.7 \times 0.5 \mathrm{~cm}$, subtending $0.7^{\circ}$ (height) $\times 0.5^{\circ}$ (width) of visual angle, divided in the center so that two contiguous vertical rectangles were formed. Half of the target was red, and the other half was green. The two colored squares were framed by black lines, so that the two colors making up a stimulus were not touching each other. There were four types of distractors: red/blue, blue/red, green/blue, and blue/green (Figure 1). The coordinates in standard CIE color space were $.632, .350$ for red; $.275, .610$ for green; and $.175, .108$ for blue. Red and blue were at $100 \%$ of maximum monitor brightness, and green was at $70 \%$ of maximum monitor brightness.

Design. A three-way, within-subjects design was used: block (1, $2,3$, and 4$) \times$ set size $(2,6,10,14,18$, or 22$) \times$ target (present vs. absent).

Apparatus and Procedure. The apparatus and procedure were the same as in the previous experiment.

\section{Results}

Figure 5 depicts the observers' mean correct RT and error rates as a function of set size for the four experimental blocks. The linear fit's intercepts of these functions show that the minimum response time was faster for present than for absent trials. The search functions relating RT $\times$ set size are indexed by the slope values, which will be discussed below.

A three-way ANOVA was performed on the correct RT (block $\times$ target $\times$ set size; Table 3 ). All main effects and interactions discussed were statistically significant $(p<.0001)$. Main effects indicated that observers' search time decreased progressively from the first to the fourth block, was faster for present than for absent targets, and increased as a function of set size. The interactions of block $\times$ target and block $\times$ set size revealed that with more practice the effects of target-a target's presence was detected faster than its absence - and set size - search time increased as the display contained more items-de-

\section{Block 1}

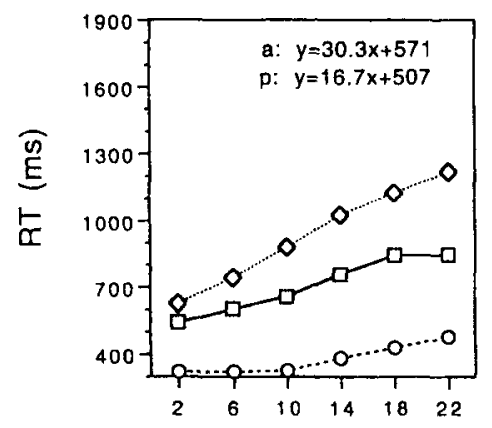

Block 2

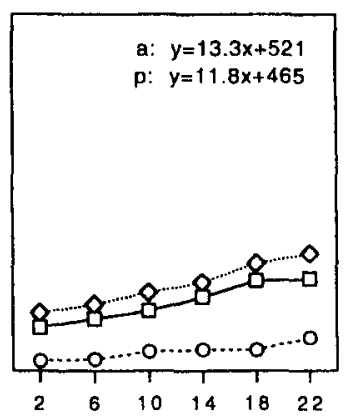

Block 3

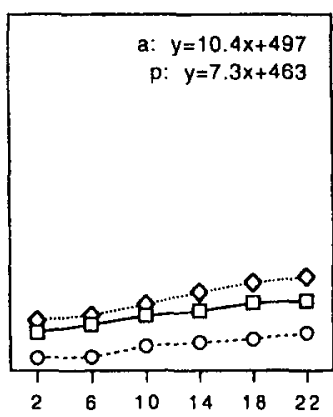

Block 4

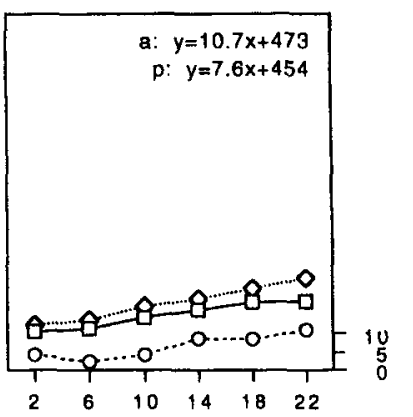

Set size

\begin{tabular}{|c|c|}
\hline$\rightarrow$ & present \\
\hline$\cdots \cdots$ & absent \\
\hline$\cdots 0 \cdots$ & $\%$ Error \\
\hline
\end{tabular}

Figure 5. Search performance in Experiment 3: RT and \% error as a function of set size for a color $\times$ color conjunction when the target could be red/green or green/red and the distractors were red/blue, blue/red, green/blue, and blue/green. 
Table 3

ANOVA Results for RT Data in Experiment 3

\begin{tabular}{lccc}
\hline Factor & $d f$ & $F$ & $p$ \\
\hline Block (B) & 3,27 & 17.90 & $<.0001$ \\
Target (T) & 1,9 & 53.79 & $<.0001$ \\
Set size (S) & 5,45 & 65.84 & $<.0001$ \\
$\mathrm{~B} \times \mathrm{T}$ & 3,27 & 11.33 & $<.0001$ \\
$\mathrm{~B} \times \mathrm{S}$ & 15,135 & 11.83 & $<.0001$ \\
$\mathrm{~T} \times \mathrm{S}$ & 5,45 & 9.07 & $<.0001$ \\
$\mathrm{~B} \times \mathrm{T} \times \mathrm{S}$ & 15,135 & 3.50 & $<.0001$ \\
\hline
\end{tabular}

creased. The interaction of target $\times$ set size showed that the effect of set size was more pronounced for absent than for present targets. A three-way interaction indicated that, with practice, the degree of the set-size effect was diminished, especially for the present targets.

For the accuracy data, an ANOVA indicated that observers were more accurate for the absent than for the present targets $[F(1,9)=60.63, p<.001]$. This common finding was discussed in Experiment 1 . The observers were also more accurate for smaller than for larger set sizes $[F(5,45)=24.75, p<.001]$, indicating that there was no SATO between set size and error rates; errors increased as RT increased, indicating that observers were not simply trading speed for accuracy (Enns \& Rensink, 1990a, 1990b).

-The design of this experiment replicated that of Wolfe et al. (1990), but the linear regression slopes were shallower than those for the color $\times$ color conjunction of Wolfe et al. (1990, Figure 6, p. 886; present, $20.7 \mathrm{msec} / \mathrm{item}$, and absent, $40.5 \mathrm{msec} /$ item), even in the first block of this experiment (present, $16.74 \mathrm{msec} / \mathrm{item}$, and absent, $30.35 \mathrm{msec} /$ item), although the absent/present ratio in this block (1.8) was similar to theirs (2). It is important to note that the error rate for this block was very similar to the error rate of Wolfe et al.'s (1990); 5\% overall and $11 \%$ for the highest set size.

The slope analysis confirmed the ANOVA results. Practice improved performance so much that the steep RT $\times$ set size slopes that characterized the first block became shallower with practice to the point of being equal to, or less than, $10 \mathrm{msec} / \mathrm{item}$ for the absent and present targets, respectively. Furthermore, as Figure 6 shows, even if practice effects were not explored, simply having allowed observers to perform 1,008 trials in a 1 -h experimental session yielded an overall efficient search (present, $10.86 \mathrm{msec} /$ item, and absent, $16.28 \mathrm{msec} /$ item). In addition, as in the previous experiments, the prediction of the serial self-terminating model that RT variability should increase more for present than for absent trials as a function of set size (Shiffrin \& Schneider, 1977) was not fulfilled. In fact, RT variability increased more for the absent than for the present targets overall, as well as in each of the four blocks of this experiment.

To conclude, although the design of this experiment increased the distractor heterogeneity and decreased the signal-to-noise ratio because the relative spatial location of the color components of the target and the distractors were not kept constant within $1 \mathrm{~h}$ of practice, the observers searched this color $\times$ color conjunction target efficiently, as reflected by a shallow $\mathrm{RT} \times$ set size slope.

\section{DISCUSSION}

The main finding of the present study, that withindimension conjunctions (color $\times$ color) can be detected efficiently as indexed by shallow RT $\times$ set size slopes, has substantial implications for visual search models. This efficient search did not depend on a particular stimulus shape; it emerged with a rectangular shape (Experiments 1 and 3 ) and with a plus sign (Experiment 2). Furthermore, the plus sign contained a black intersection which minimized the color assimilation and the local color contrast that could have been used as a cue in searching in Experiment 1; the color regions were not directly adjacent to one another. This was also the case in Experiment 3, where the colored squares were framed by black lines. In all three experiments, the slopes became shallower as practice increased, the more so if the distractors shared a color (Condition 1 of Experiments 1-3) than if they did not (Condition 2 of Experiments 1 and 2). Moreover, the search pattern did not conform to predictions from a serial self-terminating model: The RT 2:1 absent/present slope ratio did not emerge, nor was there greater RT variability for present than for absent trials as set size increased.

Wolfe et al. (1990) have stated that their finding that color $\times$ color conjunctions are searched in a "serial selfterminating" fashion (steep RT $\times$ set size slopes) repre-

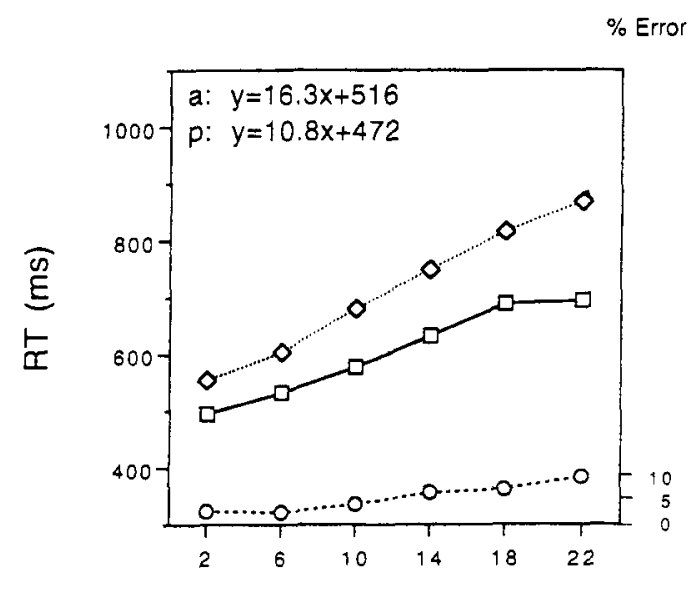

Set size

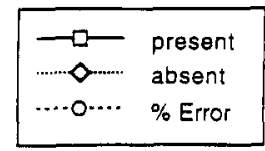

Figure 6. Overall search performance in Experiment 3: RT and $\%$ error as a function of set size for a color $\times$ color conjunction when the target could be red/green or green/red and the distractors were red/blue, blue/red, green/blue, and blue/green. 
sents an important limitation on the ability of the parallel stage of visual processing to guide the subsequent serial deployment of attention. In a between-dimension conjunction search for a red vertical item, the color module could find the set of all red items, the orientation module could find the set of all vertical items, and attention could be guided to the intersection of those two dimensions. In contrast, according to these authors, in a within-dimension search for a red/green item among red/blue and blue/green distractors, this sort of guidance would be fruitless; the color module could find the set of all red items and the set of all green items, but all target and distractors contain either red or green.

The serial steep slope found for color $\times$ color conjunctions by Wolfe et al. (1990) was not an artifact of the particular color or shapes used in the original experiments or of stimulus complexity. All 14 different stimulus configurations they tested produced search functions of at least $20 \mathrm{msec} /$ item and about 2:1 absent-to-present ratios. Moreover, the color $\times$ color search was found to be more inefficient than other well-established serial searches (e.g., T among L; Wolfe et al., 1994). In all three experiments of the present study, however, a shallow RT $\times$ set size slope resulted from the color $X$ color conjunctions when the distractors shared the blue color, whether there were one target (red/green) and two types of distractors (red/blue and blue/green) as in Experiments 1 and 2, or two possible targets (red/green or green/red) and four types of distractors (red/blue, blue/red, green/blue, and blue/green) as in Experiment 3. Furthermore, with practice, these searches became progressively more efficient. For some authors, the slopes for such searches would be considered as indicating a "parallel" search (e.g., Duncan \& Humphreys, 1989; Enns \& Rensink, 1990a, 1990b; Heathcote \& Mewhort, 1993; Quinlan \& Humphreys, 1987; Treisman \& Gormican, 1988; Treisman \& Sato, 1990; Wolfe \& Cave, 1990; Wolfe et al., 1989). In contrast to the virtually unpracticed observers described by Wolfe, even modestly practiced observers yielded different results. We attribute the difference between our results and those of Wolfe et al. (1990) to the fact that we included more trials (1,280 in Experiment 1 and 1,008 in Experiments 2 and 3 ) than they did ( 330 trials). Note, however, that this modest number of trials was conducted with naive observers (from Introduction to Psychology subject pools) within a 1-h experimental session, a conventional testing time.

According to Wolfe et al. (1990), the distinction between within-dimension and between-dimension conjunctions constrains the structure of the parallel stage of processing of visual search models. Theories of visual search purport to characterize fundamental features of the visual system, but these properties are affected by a reasonable range of practice. We maintain that before a finding is considered to constrain the structure of the parallel system, it is necessary, or at least desirable, to attain stability in the performance of observers. The inferred architecture of a system cannot be based on performance that changes after few hundred trials, which suggests that processing is in a state of flux. Furthermore, the finding that for modestly practiced observers search performance changed from what is thought to reflect "attentive" to "preattentive" processes shows the transient nature of this dichotomous distinction and challenges its stability and validity. This study also indicates that in order to make meaningful comparisons between different experimental conditions it is critical to take into account the number of trials performed by the observers. Otherwise, differences in search performance may stem from practice effects and not necessarily from inherent stimulus or task characteristics.

In addition to practice effects, search performance in our Experiments 1 and 2 may have been more efficient than those of Wolfe's experiments. Given that we were interested in isolating the effect of the color variable, we kept the relative spatial location of the color $X$ color target and distractors constant; in contrast, their color $X$ color target could be either red/green or green/red and their distractors could be either red/blue or blue/red and green/blue or blue/green in the rectangular stimulus (similar to this study's Experiment 1) or either red/white or white/red and green/white or white/green in their plus stimulus (similar to this study's Experiment 2). Note, however, that in Wolfe's Experiment 5 (Wolfe et al., 1990, Figure 6, p. 886), search performance was very similar when observers searched for a "dumbbell" in which only one of the two red-green targets and one each of the red-blue and bluegreen distractors were used $(48 \mathrm{msec} /$ item for present, and $92 \mathrm{msec} /$ item for absent) and when observers searched for a "dumbbell" in which the targets were the two possible versions of the red-green items and the distractors were the two versions each of red-blue and green-blue items ( $43 \mathrm{msec} /$ item for present, and $77 \mathrm{msec} /$ item for absent). These authors concluded that there was a serial, self-terminated search in both cases. In any case, in the present experiment, although the search was less efficient with the more heterogeneous distractors (Experiment 3 vs. Experiment 1), a pronounced practice effect indicated that it is possible to detect the color $\times$ color conjunction in an efficient way even with such a heterogeneous display.

It has been proposed that search guidance is not possible for within-dimension conjunctions because it is not possible for a one-dimensional module (e.g., color) to handle two separate requests at the same time (Wolfe et al., 1990). These authors stated that the serial nature for conjunctions of two features (e.g., red, green) of the same dimension (e.g., color) argues against models in which each feature has a modular status (Treisman, 1985) as well as against models in which no modularity exists in the parallel search (Duncan \& Humphreys, 1989). Wolfe et al. (1990) concluded that their data were consistent with a structure for the parallel stage in which each dimension provides only a single source of guidance to the subsequent serial deployment of attention. However, the eff 1 - 
cient color $\times$ color conjunction searches found in the present study show that this conclusion is not warranted. Some recent findings (e.g., Found \& Müller, 1996; Nothdurft, 1992, 1993) have suggested that the color dimension may consist of modular subdimensions representing broad categories of color (e.g., blue, green, red; Found $\&$ Müller, 1996). The efficient color $\times$ color conjunction searches found in the present experiments would be consistent with this hypothesis by implying that multiple top-down requests could be effectively handled because different information would not be competing for the same pathway and information would not have to be carried serially. However, this hypothesis has stemmed from experiments with features, thought to be searched in a preattentive fashion, and has not been directly tested with conjunctions, thought to be searched in an attentive fashion. Moreover, this idea of color modular subdimensions does not predict the finding that search performance was more efficient when the distractors shared than when they did not share a common color (Condition 1 vs. Condition 2 of Experiments 1 and 2).

Furthermore, Wolfe et al. (1990) reasoned that if it were possible to guide attention away from the distractors' shared color (all blue locations), the only remaining location would have been the target and a parallel search would have been attained. Hence, according to these authors, the serial search for a color $\times$ color conjunction rules out direct inhibition in the search process. However, the present study has shown that, with some practice, a shallow slope describes the search for withindimension color conjunctions. This finding supports hypotheses of distractor inhibition that have been proposed earlier. They propose that the distractors can be inhibited because they have a feature that is not shared with the target (e.g., Duncan, 1995; Duncan \& Humphreys, 1989; Humphreys \& Müller, 1993; Treisman \& Sato, 1990; Treisman et al., 1992). Our findings suggest that this inhibition may be stronger when, in addition to this display characteristic, the distractors share a common value. The finding that the red/green target was detected more efficiently among red/blue and blue/green distractors (Condition 1 of Experiments 1 and 2) than among $\mathrm{red} / \mathrm{blue}$ and yellow/green (Experiment 1's Condition 2) or among red/blue and pink/green distractors (Experiment 2's Condition 2) suggests that inhibition of the blue color may have guided the search in a more direct way than when the distractors did not share a common color.

More recently, Wolfe et al. (1994) have found that searches can be efficient when observers search for the color of a whole item conjoined with the color of a component part (part-whole color $\times$ color conjunctions: for example, find the red house with yellow windows among red houses with blue windows and blue houses with yellow windows). Thus, Wolfe $(1994,1996 a$; Wolfe et al., 1994) has concluded that attention can be guided to a two-colored item when the relationship between the colored regions is hierarchical, as well as to an item defined by the conjunction of the color and orientation of an item, but that attention cannot be guided to a target defined by the conjunction of the colors of two parts. Indeed, the current version of GSM (2.0) models the serial search of a color $\times$ color conjunction by making it impossible to specify two colors or two orientations for search at the same time (Wolfe, 1994). The shallow slopes that emerged in the present study question this aspect of GSM and suggest that this model would have to postulate that, under certain circumstances (see below), either attention could be guided by the conjunction of the colors of two parts or attention would not be necessary to detect a color $X$ color conjunction.

It may be that within-dimension conjunctions are harder than between-dimension conjunctions, and/or that practice is more needed for a within- than for a betweendimension conjunction; however, once observers' performance is stable, the guidance that features belonging to one or to two dimensions provide may not differ that much. In any case, the present finding that observers' performance with color $X$ color conjunctions improved with practice and could be described by shallow slopes suggests that the conclusions about the structure of the parallel stage of visual search models reached by Wolfe et al. need to be reevaluated. Furthermore, using distractors that did not share a feature (Condition 2 of Experiments 1 and 2) revealed an interaction between practice and distractor type. In both Experiment 1 and Experiment 2, the effects of practice were more pronounced when the two types of distractors shared a feature (Condition 1) than when they did not (Condition 2). In fact, in Experiment 2's Condition 2, search did not improve between the third and fourth blocks, whereas the search kept improving in Condition 1. In addition, in Experiment 3, although observers were performing a more difficult task, searching for one of two targets among four different distractors, with practice, a shallow RT $\times$ set size slope characterized observers' performance. We suggest that distractors sharing the blue color facilitated performance because this color induced perceptual grouping. As observers became more familiar with the task, their search strategy may have switched from looking for the target per se to relying more on the distractors so that, via spreading suppression, they could have rejected the distractors in a parallel fashion (Duncan \& Humphreys, 1989).

In contrast, although observers' performance improved with practice when the blue color was not common to all distractors, the search did not improve as much in Condition 2 of Experiments 1 and 2 as in Condition 1 of these experiments and in Experiment 3 . The introduction of the yellow color in half of the distractors of Experiment $l$ and of the pink color in half of the distractors of Experiment 2 enhanced display noise by increasing the heterogeneity of the distractors; the more noise, the harder the target is to find (e.g., Duncan \& Humphreys, 1989; Farmer \& Taylor, 1980; Müller, Heller, \& Ziegler, 1995; Wolfe et al., 1989). Thus, despite the fact that 
GSM could explain why performance was better when distractors shared a color (Condition 1) than when they did not (Condition 2), this model cannot explain our other results: the shallow slope for a color $\times$ color conjunction and the differential practice effects on these two conditions.

Although grouping is generally discussed in the context of feature searches, Duncan and Humphreys (1989, 1992) have related it to conjunction searches as well (see also Grossberg et al., 1994; McLeod et al., 1988; Nakayama \& Silverman, 1986; Poisson \& Wilkinson, 1992; Treisman, 1982; Treisman \& Sato, 1990). They see features and conjunctions as tapping into a common process whereby performance is determined by levels of targetdistractor similarity and by similarity among distractors, rather than reflecting preattentive versus attentive processes. This study shows that perceptual organization, induced by color, aids performance not only in feature searches (Bundesen \& Pedersen, 1983; Carrasco \& Chang, 1995), but also in conjunction searches. Although grouping of distractors by color similarity and proximity has been established, the way such grouping is used in the search process has not been specified (e.g., Banks \& Prinzmetal, 1976; Bundesen \& Pedersen, 1983; Farmer \& Taylor, 1980; Heathcote \& Mewhort, 1993; Treisman $\&$ Gelade, 1980). We suggest that exploring practice effects could shed some light onto the way in which the search strategy may be affected by the perceptual grouping the display affords.

To conclude, this study has shown that even though there may be several limitations on parallel processing in the visual system, the nonshared features between the distractors and the target can afford inhibition to guide the search, especially if distractors can be perceptually grouped and observers are given some practice with the display. To explain this finding, GSM would have to interpret how attention could be guided to a target defined by the conjunction of the colors of two parts or that a parallel process is possible for such a within-dimension conjunction. In a recent chapter, Wolfe (1996b) asked: "When a task becomes efficient, as some tasks do with practice, is the observer building a new parallel process or isolating an attention guiding signal from one existing preattentive process in the midst of the noise from the other processes?" (p. 35). In any case, by suggesting that the parallel stage of the processing of visual search models can handle at least two requests from the same module (color), the findings of the present study have implications for the structure of the parallel stage of processing of visual search models. To account for the findings of the present study, GSM (e.g., Wolfe, 1994, 1996a, 1996b; Wolfe et al., 1989; Wolfe et al., 1990) would have to be modified to allow for distractor inhibition and distractor grouping. We concur with authors who state that the visual system's ability to organize visual items into perceptual objects is a fundamental aspect of visual selection, and that comprehensive theories of vision, visual attention, and visual search require a satisfactory account of perceptual organization (Carrasco \& Chang, 1995; Prinzmetal \& Keysar, 1989; Yantis, 1992).

\section{REFERENCES}

BanKs, W. P., \& Prinzmetal, W. (1976). Configurational effects in visual information processing. Perception \& Psychophysics, 19, 361-367.

BECK, J. (1966). Effect of orientation and of shape similarity on perceptual grouping. Perception \& Psychophysics, 1, 300-302.

BECK, J. (1967). Perceptual grouping produced by line figures. Perception \& Psychophysics, 2, 491-495.

BECK, J. (1982). Textural segmentation. In J. Beck (Ed.), Organization and representation in perception (pp. 285-318). Hillsdale, NJ: Erlbaum.

Ben-Av, M. B., SAGi, D., \& Braun, J. (1992). Visual attention and perceptual grouping. Perception \& Psychophysics, 52, 277-294.

Bravo, M. J., \& Blake, R. (1990). Preattentive vision and perceptual groups. Perception, 19, 515-522.

Bundesen, C., \& Pedersen, L. F. (1983). Color segregation and visual search. Perception \& Psychophysics, 33, 487-493.

Carrasco, M., \& Chang, I. (1995). The interaction of objective and subjective organizations in a localization search task. Perception \& Psychophysics, 57, 1134-1150.

Carrasco, M., Evert, D. L., Chang, I., \& Katz, S. M. (1995). The eccentricity effect: Target eccentricity affects performance on conjunction searches. Perception \& Psychophysics, 57, 1241-1261.

CARRAsco, M., \& FrIEDER, K. (1997). Cortical magnification neutralizes the eccentricity effect in visual search. Vision Research, 37, 63-82.

Carrasco, M., \& Yeshurun, Y. (1998). The contribution of covert attention to the set-size and eccentricity effects in visual search. Journal of Experimental Psychology: Human Perception \& Performance, 24, 673-692.

CAVE, K. R., \& Wolfe, J. M. (1990). Modeling the role of parallel processing in visual search. Cognitive Psychology, 22, 225-271.

De WeerT, C. M. M., \& Spillman, L. (1995). Assimilation: Asymmetry between brightness and darkness? Vision Research, 35, 14131419.

DunCan, J. (1984). Selective attention and the organization of visual information. Journal of Experimental Psychology: General, 113, 501517.

Duncan, J. (1995). Target and nontarget grouping in visual search. Perception \& Psychophysics, 57, 117-120.

DunCaN, J., \& Humphreys, G. W. (1989). Visual search and stimulus similarity. Psychological Review, 96, 433-458.

Duncan, J., \& Humphreys, G. W. (1992). Beyond the search surface: Visual search and attentional engagement. Journal of Experimental Psychology: Human Perception \& Performance, 18, 578-588.

EgETH, H. E., FolK, C. L., \& Mullin, P. A. (1989). Spatial parallelism in the processing of lines, letters, and lexicality. In B. E. Shep \& S. Ballesteros (Eds.), Object perception: Structure and process (pp. 19-52). Hillsdale, NJ: Erlbaum.

Egeth, H. E., Virzi, R. A., \& Garbart, H. (1984). Searching for conjunctively defined targets. Journal of Experimental Psychology: Human Perception \& Performance, 10, 32-39.

ENNS, J. T., \& RENSINK, R. A. (1990a). Influence of scene-based properties on visual search. Science, 247, 721-723.

ENNS, J. T., \& RENSink, R. A. (1990b). Sensitivity to three-dimensional orientation in visual search. Psychological Science, 1, 323-326.

ENNS, J. T., \& RENSINK, R. A. (1992). VScope software and manual: Vision testing software for the Macintosh. Vancouver, BC: University of British Columbia, Micropsych software.

ERIKSEN, C. W. (1952). Location of objects in a visual display as a function of the number of dimensions on which the objects differ. Journal of Experimental Psychology, 44, 56-60.

ERIKSEN, C. W. (1953). Object location in a complex perceptual field. Journal of Experimental Psychology, 45, 126-132.

FARMER, E. W., \& TAYLOR, R. M. (1980). Visual search through color displays: Effects of target-background similarity and background uniformity. Perception \& Psychophysics, 27, 267-272.

Found, A., \& Müller, H. J. (1996). Searching for unknown feature 
targets on more than one dimension: Investigating a "dimensionweighting" account. Perception \& Psychophysics, 58, 88-101.

Friedman-Hill, S., \& Wolfe, J. W. (1995). Second-order parallel processing: Visual search for the odd item in a subset. Journal of Experimental Psychology: Human Perception \& Performance, 21, 531-551.

Grossberg, S., Mingolla, E., \& Ross, W. D. (1994). A neural theory of attentive visual search: Interactions of boundary, surface, spatial, and object representations. Psychological Review, 101, 470-489.

Heathcote, A., \& Mewhort, D. J. K. (1993). Representation and selection of relative position. Journal of Experimental Psychology: Human Perception \& Performance, 19, 488-516.

HitT, W. D. (1961). An evaluation of five different abstract coding methods-Experiment IV. Human Factors, 3, 120-130.

Humphreys, G. W., \& Müller, H. J. (1993). Search via recursive rejection (SERR): A connectionist model of visual search. Cognitive Psychology, 25, 43-110.

Humphreys, G. W., Quinlan, P. T., \& Riddoch, M. J. (1989). Grouping processes in visual search: Effects with single- and combinedfeature targets. Journal of Experimental Psychology: General, 118, 258-279.

JuLESZ, B. (1980). Spatial nonlinearities in the instantaneous perception of textures with identical power spectra. Philosophical Transactions of the Royal Society of London, 290, 83-94.

Kahneman, D., \& Henik, A. (1981). Perceptual organization and attention. In M. Kubovy \& J. R. Pomerantz (Eds.), Perceptual organization (pp. 423-456). Hillsdale, NJ: Erlbaum.

Kinchla, R. A. (1992). Attention. Annual Review of Psychology, 43, 711-742.

Klein, R., \& Farrell, M. (1989). Search performance without eye movements. Perception \& Psychophysics, 46, 476-482.

LABERGE, D. (1975). Acquisition of automatic processing in perceptual and associative learning. In P. M. A. Rabbitt \& S. Dornic (Eds.), Attention and performance $V$. New York: Academic Press.

LoGAN, G. D. (1988). Toward an instance theory of automatization. Psychological Review, 95, 492-527.

Logan, G. D. (1994). Spatial attention and the apprehension of spatial relations. Journal of Experimental Psychology: Human Perception \& Performance, 20, 1015-1036.

MCLeOD, P., Driver, J., \& CRISP, J. (1988). Visual search for a conjunction of movement and form is parallel. Nature, 332, 154-155.

Moraglia, G. (1989a). Display organization and the detection of horizontal line segments. Perception \& Psychophysics, 45, 265-272.

Moraglia, G. (1989b). Visual search: Spatial frequency and orientation. Perceptual \& Motor Skills, 69, 675-689.

Müller, H. J., Heller, D., \& Ziegler, J. (1995). Visual search for singleton feature targets within and across feature dimensions. Perception \& Psychophysics, 57, 1-17.

Nakayama, K., \& Silverman, G. H. (1986). Serial and parallel processing of visual feature conjunctions. Nature, 320, 264-265.

NeISSER, U. (1967). Cognitive psychology. New York: Appleton-CenturyCrofts.

Nothdurft, H.-C. (1992). Feature analysis and the role of similarity in preattentive vision. Perception \& Psychophysics, 52, 355-375.

NothDURFT, H.-C. (1993). The role of features in preattentive vision: Comparison of orientation, motion and color cues. Vision Research, 33, 1937-1958.

Palmer, S., \& Rock, I. (1994). Rethinking perceptual organization: The role of uniform connectedness. Psychonomic Bulletin \& Review, 1, 29-55.

PASHler, H. (1987). Detecting conjunctions of color and form: Reassessing the serial search hypothesis. Perception \& Psychophysics, 41, 191-201.

Poisson, M. E., \& Wilkinson, F. (1992). Distractor ratio and grouping processes in visual conjunction search. Perception, 21, 21-38.

Pomerantz, J. R. (1981). Perceptual organization in information processing. In M. Kubovy \& J. R. Pomerantz (Eds.), Perceptual organization (pp. 141-180). Hillsdale, NJ: Erlbaum.

Ponte, D., Rechea, C., \& Sampedro, M. J. (1995). Efecto de la homogeneidad y la organización de las exposiciones en una tarea de búsqueda visual con objetivos múltiples [The effect of display homogeneity and organization in a visual search task with multiple targets]. Cognitiva, 7, 131-148.

Prinzmetal, W., \& Banks, W. P. (1977). Good continuation affects visual detection. Perception \& Psychophysics, 21, 389-395.

Prinzmetal, W., \& Keysar, B. (1989). Functional theory of illusory conjunctions and neon colors. Journal of Experimental Psychology: General, 118, 165-190.

Quinlan, P. T., \& Humphreys, G. W. (1987). Visual search for targets defined by combinations of color, shape, and size: An examination of the task constraints on feature and conjunction searches. Perception \& Psychophysics, 41, 455-472.

Rechea, C., Ponte, D., \& Risso, A. (1992). El efecto de característica y la práctica en tareas híbridas de búsqueda visual y en la memoria [The effect of practice on heterogeneous visual and memory searches]. Revista de Psicologia General y Aplicada, 45, 5-12.

Schneider, W., Dumas, S. T., \& Shiffrin, R. M. (1984). Automatic and control processing and attention. In R. Parasuraman \& D. R. Davies (Eds.), Varieties of attention (pp. 1-27). Orlando, FL: Academic Press.

SChNeIDER, W., \& Shiffrin, R. (1977). Controlled and automatic human information processing: Detection, search and attention. Psychological Review, 84, 1-66.

Shiffrin, R., \& SchneIder, W. (1977). Controlled and automatic human information processing: II. Perceptual learning, automatic attending, and a general theory. Psychological Review, 34, 129-190.

Sireteanu, R., \& RetTenbach, R. (1995). Perceptual learning in visual search: Fast, enduring, but non-specific. Vision Research, 35 , 2037-2043.

TownsEnd, J. T. (1972). Some results concerning the identifiability of parallel and serial processes. British Journal of Mathematical \& Statistical Psychology, 25, 168-199.

TownsEND, J. T. (1990). Serial versus parallel processing: Sometimes they look like Tweedledum and Tweedledee but they can (and should) be distinguished. Psychological Science, 1, 46-54.

Treisman, A. (1977). Focused attention in the perception and retrieval of multidimensional stimuli. Perception \& Psychophysics, 22, 1-11.

Treisman, A. (1982). Perceptual grouping and attention in visual search for features and for objects. Journal of Experimental Psychology: Human Perception \& Performance, 8, 194-214.

Treisman, A. (1985). Preattentive processes in human vision. In Z. W. Pylyshyn (Ed.), Computational processes in human vision: An interdisciplinary perspective (pp. 341-369). Norwood, NJ: Ablex.

Treisman, A. (1988). Features and objects: The Fourteenth Bartlett Memorial Lecture. Quarterly Journal of Experimental Psychology, 40A, 194-214.

Treisman, A. (1993). The perception of features and objects. In A. D. Baddeley \& L. Weiskrantz (Eds.), Attention: Selection, awareness, and control. A tribute to Donald Broadbent (pp. 5-35). Oxford: Oxford University Press, Clarendon Press.

Treisman, A., \& Gelade, G. (1980). A feature integration theory of attention. Cognitive Psychology, 12, 97-136.

TREISMAN, A., \& Gormican, S. (1988). Feature analysis in early vision: Evidence from search asymmetries. Psychological Review, 95, 15-48.

Treisman, A., \& Sato, S. (1990). Conjunction search revisited. Journal of Experimental Psychology: Human Perception \& Performance, $16,459-478$

Treisman, A., Vieira, A., \& Hayes, A. (1992). Automaticity and preattentive processing. American Journal of Psychology, 105, 341-362.

VAN ZANDT, T., \& TOWNSEND, J. T. (1993). Self-terminating versus exhaustive processes in rapid visual and memory search: An evaluative review. Perception \& Psychophysics, 53, 563-580.

WOLFE, J. M. (1992). The parallel guidance of visual attention. Current Directions in Psychological Science, 1, 124-128.

WOLFE, J. M. (1994). Guided Search 2.0: A revised model of visual search. Psychonomic Bulletin \& Review, 1, 202-238.

WOLFE, J. M. (1996a). Extending guided search. Why guided search needs a preattentive "item map." In A. F. Kramer, M. G. H. Coles, \& G. D. Logan. Converging operations in the study of visual selective 
attention (pp. 247-270). Washington, DC: American Psychological Association.

Wolfe, J. M. (1996b). Visual search. In H. Pashler (Ed.), Attention (pp. 13-74). Hove, U.K.: Psychology Press.

WolfE, J. M., \& CAVE, K. R. (1990). Deploying visual attention: The guided-search model. In A. Blake \& T. Troschianko (Eds.), AI and the eye (pp. 80-103). New York: Wiley.

Wolfe, J. M., Cave, K. R., \& Franzel, S. L. (1989). Guided search: An alternative to the feature integration model for visual search. Journal of Experimental Psychology: Human Perception \& Performance, 15, 419-433.

Wolfe, J. M., Friedman-Hill, S. R., \& Bilsky, A. B. (1994). Parallel processing of part-whole information in visual search tasks. Perception \& Psychophysics, 55, 537-550.

Wolfe, J. M., Yu, K. P., Steward, M. I., Shorter, A. D., FriedmanHiLl, S. R., \& CAVE, K. R. (1990). Limitations on the parallel guidance of visual search: Color $\times$ color and orientation $X$ orientation conjunctions. Journal of Experimental Psychology: Human Perception \& Performance, 16, 879-892.

YANTIS, S. (1992). Multielement visual tracking: Attention and perceptual organization. Cognitive Psychology, 24, 295-340.

(Manuscript received July 17,1997 ;

revision accepted for publication October 23, 1997.) 